\title{
A CONSCIÊNCIA HISTÓRICA COMO POTENCIAL PARA LEITURA DE MUNDO
}

THE HISTORICAL CONSCIOUSNESS AS A POTENTIAL FOR READING WORLD

Vera Lucia Trennepoh/ ${ }^{1}$

\begin{abstract}
RESUMO: O texto analisa o desenvolvimento da consciência histórica, entendida como uma categoria de operação mental, fundamental no processo de empoderamento dos sujeitos, que a todo o momento são desafiados a fazerem a leitura da realidade que estão inseridos, como pessoas ou como profissionais. Realidade essa que é complexa, marcada pelo acelerado progresso científico e tecnológico, que pode atender às necessidades básicas humanas, porém a forma como isso vai ocorrer depende dos sujeitos. A abordagem metodológica orienta-se na perspectiva de uma pesquisa qualitativa e dialética em educação, privilegia reflexões e conceitos das obras de Jörn Rüsen. O resultado desse estudo considera as vivências dos alunos nas aulas de história, para compreender os desafios colocados para essa área, na busca de uma nova relação com o conhecimento, que não pode mais estar marcada pelo estudo do passado pelo passado. Assim, os diversos profissionais deverão buscar na tradição aspectos para compreender a realidade, como também para intervir em sua dinâmica, numa perspectiva de futuro.
\end{abstract}

Palavras-chave: Formação histórica. Conhecimento histórico. Consciência histórica.

\begin{abstract}
The text analyzes the development of historical consciousness, understood as a category of mental operation, essential in the process of empowerment of the subjects, who at any moment are challenged to make the reading of the reality that they are inserted, as persons or as professionals. That reality is complex, marked by accelerated scientific and technological progress, which can meet the basic human needs, but how this will occur depends on the subject. The methodological approach is from the perspective of a qualitative research and dialectics in education, focuses on reflections and concepts of Jörn Rüsen. The result of this study considers the experiences of students in history, to understand the challenges posed to this area in search of a new relationship with knowledge, that can no longer be selected by the study of the past in the past. Thus, the various professionals should seek in the aspects to understand the reality, but also to intervene in its dynamics, for the future.
\end{abstract}

Key words: Historical formation. Historical knowledge. Historical consciousness.

1 Doutora em Educação nas Ciências pela Unijuí. Professora do Curso de História da mesma universidade. 


\section{Introdução}

Este texto se constitui a partir de um esforço em explicitar algumas questões analisadas na tese de doutorado, defendida em 2014, no Programa de PósGraduação Stricto Sensu em Educação nas Ciências no Curso de Doutorado da UNIJUI - Universidade Regional do Noroeste do Rio Grande do Sul. A pesquisa desenvolvida, naquele momento, teve sua origem em questões vivenciadas e observadas ao longo da experiência de atuação como docente universitária ligada ao ensino, pesquisa e extensão na área da História, bem como a partir de entrevistas, com questões semiestruturadas, realizadas com estudantes ingressantes nos cursos da universidade. Os dados oriundos da experiência profissional e a sistematização da atividade empírica foram categorizadas, para entender a compreensão dos alunos em relação a sua formação histórica. Aqui serão analisados alguns dos aspectos percebidos nesse estudo, destacando a necessidade e o potencial que o desenvolvimento da consciência histórica representa numa sociedade dinâmica e em constante transformação.

A experiência acadêmica e as entrevistas com alunos, que estavam no primeiro semestre do seu curso de graduação, foram desenvolvidas no âmbito de uma universidade comunitária, que sempre buscou uma inserção na comunidade local. Nas palavras de Mario Osorio Marques (1984, p. 15):

[...] instituição de ensino superior, particular e interiorana, inserida, de forma original e criativa, na dinâmica de uma região em processo de transformações rápidas e profundas. Trata-se da Faculdade de Filosofia, Ciências e Letras de Ijuí (FAFI), implantada em 1957 como estabelecimento pioneiro do ensino superior no noroeste do Rio Grande do Sul, à qual sucedeu, em 1969, a Fundação de Integração, Desenvolvimento e Educação do Noroeste do Estado (FIDENE), mantenedora dos Centros Integrados de Ensino Superior de Ijuí, atualmente em processo de transformação para Universidade de Ijuí (UNIJUÍ).

A Unijuí conquistou o seu reconhecimento como universidade no final da ditadura (1964-1985) e início da nova república, como forma de reconhecimento do trabalho de qualidade desenvolvido, desde sua origem, junto à comunidade local. A formação de professores para a educação básica foi o mote principal de 
sua criação e os cursos de Licenciatura constituíram a centralidade da estrutura e das ações institucionais ao longo de sua trajetória.

A partir do reconhecimento como universidade, a Unijuí passou a expandir suas atividades por meio da abertura de cursos nas áreas das ciências sociais aplicadas, da saúde, das ciências agrárias, das engenharias e tecnologias. No início dos anos 90 formalizou seu processo de regionalização com a criação de novos câmpus e núcleos universitários em vários municípios da região e qualificou sua atuação com a criação dos programas de Pós-Graduação stricto sensu. Mesmo assim, no contexto atual, também está sendo atingida pela crise nos cursos de Licenciatura, levando ao fechamento de alguns cursos e outros encontram dificuldades para a sua continuidade, devido à baixa procura pelos cursos de formação de professores.

Os cursos de Licenciatura da Unijuí, dentre os quais o Curso de História, têm como característica a profunda inserção no contexto educacional da região. Mais do que formar professores para atender à demanda do mercado de trabalho, a atividade acadêmica compreende a interação permanente com os sistemas de ensino (públicos e privados), a análise da dinâmica educacional, a reflexão sobre os problemas e a elaboração de propostas de intervenção para superar as dificuldades e alcançar melhores níveis de qualidade.

Na região de Ijuí/RS, por exemplo, o Projeto de Estudos Sociais, desenvolvido na década de 80 , por meio de ampla articulação interinstitucional, possibilitou a revitalização do ensino destas áreas, em que novas alternativas para o ensinar e o aprender História foram construídas. Este Projeto produziu mudanças na sistemática de sala de aula, qualificando o trabalho realizado pelos professores. Mesmo assim, na implementação do proposto foi possível perceber alguns dos problemas, das dificuldades e das insuficiências, que dificultaram a consolidação dos resultados esperados pelo grupo de professores. ${ }^{2}$ Ressalto que, a preocupação em implementar propostas inovadoras também ocorreu em outros estados, como, por exemplo, São Paulo e Minas Gerais, analisado pela Selva Guimaraes Fonseca em seu Livro Os Caminhos da História ensinada.

Assim, a abertura política e o processo de redemocratização da sociedade brasileira impulsionaram o surgimento de amplas possibilidades de repensar e revisar as diretrizes e as práticas de ensino no país. O debate sobre a educação

2 Maiores informações sobre o Projeto Estudos Sociais em $O$ ensino de História em questão: os caminhos de uma experiência publicado pela Editora Unijuí. 
brasileira produziu uma nova Lei de Diretrizes e Bases da Educação Nacional (BRASIL, 1996) e uma gama de novas orientações, parâmetros curriculares, propostas pedagógicas, etc. Fazer o debate sobre estas novas diretrizes com os professores que atuam nas escolas das redes municipal e estadual de ensino continua sendo um desafio para as universidades. Percebe-se que mais do que repassar os ditames oficiais, é preciso compreender a realidade de cada sistema escolar e construir propostas de avanço no sentido das orientações oficiais, considerando a realidade que as instituições estão inseridas.

A efetividade deste trabalho depende da capacidade de reflexão das universidades para fazer a leitura das circunstâncias, e da criatividade para elaborar alternativas com possibilidade de sucesso num processo de interação. A cada novo momento, alternativas ${ }^{3}$ são construídas que visam garantir uma maior relação com a comunidade local, mais especificamente, com as escolas, sendo fundamental para o processo de qualificação da educação brasileira.

As mudanças de contexto trazem à tona uma perspectiva teórica, presente em novas diretrizes curriculares, que, em boa medida, apontam para a importância do conhecimento histórico, e percebe-se que isso não é tranquilo entre os sujeitos implicados no processo ensino aprendizagem. Isso ficou evidente na interação com alunos que ingressavam na universidade, pois, como integrante de um grupo interdisciplinar de docentes que ministram a disciplina de Formação e Desenvolvimento da Sociedade Brasileira $(F D S B)^{4}$, que faz parte do rol de disciplinas que visam contribuir com a Formação Geral Humanista dos estudantes, várias afirmações eram colocadas pelos alunos, que refletiam a pouca valorização do conhecimento histórico. Ressalta-se, que a universidade sempre teve como preocupação, além de garantir uma boa bagagem da área especifica, garantir que os estudantes tivessem possibilidade de conhecer a realidade do seu país, através do estudo e análises em perspectiva histórica

3 Uma alternativa a ser destacada diz respeito Programa de Iniciação a Docência - PIBID, do qual sou coordenadora do subprojeto de História, que para além de qualificar a formação dos estudantes, possibilita uma relação com as escolas.

4 Esta disciplina foi proposta em 1967, como Cultura Brasileira, ministrada em todos os cursos durante dois semestres letivos (120 horas-aula). A partir de 1972, por exigência legal, passou a ser ministrada com a denominação de Estudo de Problemas Brasileiros I e II (EPB). Com o fim da exigência legal, em 2000 a Unijuí reestruturou a Formação Geral e Humanística e ela passou a ser chamada de Formação e Desenvolvimento Brasileiro (FDB). A partir de 2014 foi denominada de Formação e Desenvolvimento da Sociedade Brasileira (FDSB). 
A relação com alunos que, no ano anterior, tinham concluído o Ensino Médio, contribuiu para entender o seu processo de formação e suas expectativas em relação à formação universitária, pois, em vários momentos, relatavam as experiências vivenciadas no ensino fundamental e médio. O contato com esses alunos possibilitou a elaboração de questões, que serviram como guia nas entrevistas, que visavam entender a leitura dos mesmos em relação à sua formação histórica.

As afirmações ouvidas durante as aulas na universidade, também eram colocadas por professores durantes as extensões. Estas questões me instigaram a querer entender o processo de formação histórica, pois os documentos e contexto (ampliação de filmes, jogos históricos) demonstravam a importância dos estudos históricos. Mesmo assim, percebia-se que essas questões não eram compreendidas desta forma por um bom número dos sujeitos implicados no processo de ensino e aprendizagem. Os professores das escolas, portanto, destacavam o desinteresse dos mesmos pelos estudos, não ficando restrito à área da História. Em função disso, tornava-se necessário dar voz aos alunos para entender as suas vivências nas aulas de História. Essas leituras revelavam também suas expectativas quanto à sua qualificação profissional.

Para apresentar parte dessa sistematização, optou-se por destacar a dinamicidade da sociedade atual, que requer sujeitos capazes de compreender a realidade. Num segundo momento, se discute a consciência Histórica analisada por Rüsen, como um potencial para a leitura da realidade. Assim, essa análise, contribui para compreendermos e enfrentarmos os desafios, no processo do constante reinventar-se, para garantir uma nova relação com o conhecimento histórico.

\section{A dinamicidade da sociedade atual}

A dinâmica do mundo atual tem gerado variados desafios para os profissionais e a sociedade. O acelerado progresso científico e tecnológico proporciona o desenvolvimento das comunicações, a integração das atividades econômicas e a intensificação das relações sociais em âmbito planetário. Esse contexto aponta diretamente para a necessidade de qualificação profissional de 
alto nível, tanto em perspectiva dos conhecimentos de sua área especifica como em relação à realidade que irão atuar como pessoas e profissionais, fazendo suas escolhas.

Pela primeira vez na História da humanidade um conjunto de técnicas de produção e de interação social envolve o planeta como um todo, atingindo de forma instantânea a vida das pessoas, das empresas e das instituições. Ser atingido ou ter acesso à informação não garante por si só a sua compreensão, mas possibilita que pessoas e entidades sejam mobilizadas no imediato e, tomem conhecimento do que está acontecendo, podendo se posicionar ou não. A confluência dos momentos, que ocorre atualmente, demonstra a interdependência dos acontecimentos, da capacidade de mobilização dos sujeitos, que vivem num mundo globalizado.

As características da sociedade atual podem ser explicitadas pelos elementos que constituem a globalização. Para Milton Santos (2010, p. 24), "Os fatores que contribuem para explicar a arquitetura da globalização atual são: a unicidade da técnica, a convergência dos momentos, a cognoscibilidade do planeta e a existência de um motor único na história, representado pela mais-valia". Então, a unicidade da técnica permite que no mundo inteiro se produza da mesma forma, que tenhamos como conhecer os recursos, as potencialidades, os limites e as ameaças do mundo, tudo no seu imediato e ao mesmo tempo. Mas, todas estas questões são permeadas pela busca incessante do lucro, da mais-valia, em que empresas, grupos econômicos ou pessoas disputam essa riqueza. Por isso, nas sociedades nem todos têm condições de participar da produção ou mesmo usufruir o que é produzido.

A questão é saber aproveitar os benefícios e entender os problemas que ela pode gerar. Entender que o problema não está na globalização em si, mas na forma como os benefícios, associados a esse sistema, são distribuídos na sociedade. O grande desafio está em compreender esse processo e buscar alternativas para enfrentar os problemas e utilizar de forma adequada as potencialidades. Segundo Sen e Kliksberg (2010, p. 23), "o ponto central é como fazer um bom uso dos formidáveis benefícios do intercurso econômico e do progresso tecnológico de maneira a atender de forma adequada aos interesses dos destituídos e desfavorecidos". 
Tais circunstâncias, entretanto, ampliam a complexidade do mundo e dificultam a tarefa de compreensão da realidade. Os avanços tecnológicos possibilitam o acesso às informações, porém para entendê-las em sua amplitude e profundidade, torna-se necessário avançar mecanismos e estratégias que possibilitam a sua compreensão. Milton Santos (2010) ressalta que o mundo é confuso e confusamente percebido. $\mathrm{E}$, ainda, segundo o autor;

\begin{abstract}
Quando aceitamos pensar a técnica em conjunto com a política e admitimos atribuir-lhe outro uso, ficamos convencidos de que é possível acreditar em uma outra globalização e em um outro mundo. O problema central é o de retomar o curso da história, isto é, de recolocar o homem no seu lugar central (Santos, 2010, p. 125).
\end{abstract}

A comunicação, entretanto, altamente desenvolvida em suas técnicas, difunde leituras e mensagens carregadas de sentidos que nem sempre têm a intenção de informar e instruir, mas de influir na opinião pública, pois traz à tona uma leitura da realidade, já filtradas. Nem sempre os sujeitos percebem que as ações do aqui e agora são condicionadas, por exemplo, por circunstâncias históricas, refletem um tempo e um lugar, e de que se olhadas de forma fragmentada, não terão a possibilidade de sua compreensão. O desafio está em contribuir para que as pessoas possam fazer sínteses relevantes sobre as dinâmicas observadas e elaborar quadros interpretativos consistentes da realidade.

A sociedade é dinâmica, está em constante transformação e não pode ser vista como algo estático. Então, as pessoas devem ter noção desse movimento, compreender esse processo que influi nas suas vidas. Os movimentos podem ser determinados pelas condições históricas (objetivas) ou pelas escolhas e decisões (subjetivas) dos sujeitos sociais, majoritariamente por alguma combinação entre as mesmas, como observa Freire (2005, p. 41): "Não se pode pensar em objetividade sem subjetividade". As forças políticas, os sujeitos sociais (pessoas e profissionais) contribuem para definir o rumo dos movimentos, conscientemente ou não, por ação, reação ou omissão, em que responsabilidades devem ser compartilhadas e assumidas pelos diferentes grupos sociais.

A realidade social (objetiva) é produto das ações dos homens (subjetivas), em que dialeticamente um influi sobre o outro. Os alunos e a coletividade 
necessitam conhecer a realidade, para que façam as suas escolhas da forma mais consciente possível, pois são as pequenas ações que constroem o mundo em que estamos inseridos. Como Freire (2005) já destacava, que não é uma questão de explicar, "mas em dialogar com elas sobre a sua ação".

Os rumos da sociedade são definidos cada vez mais pelos sujeitos por intermédio das organizações, com capacidades de ler a realidade e se comprometer com os rumos da humanidade. Enquanto o avanço das ciências e das técnicas amplia as possibilidades, garantindo maior facilidade em prover o atendimento das necessidades básicas dos seres humanos, a forma como isso ocorre depende da capacidade política, buscando opções pertinentes de utilização destas potencialidades (SANTOS, 2010).

Pode-se ressaltar que a realidade que os sujeitos vivem e atuam é complexa e está em alta velocidade de transformação, exigindo profissionais com, além de conhecimento técnico e tecnológico, grande capacidade para se situar no contexto e compreender os determinantes do desenvolvimento em que estão inseridos. A História, entretanto, numa nova perspectiva teórica, não mais numa visão positivista, qualifica o processo de reflexão sobre a dinâmica da sociedade.

Mesmo assim, a importância da reflexão histórica, nem sempre é percebida desta forma pelos sujeitos (professores e alunos), pois no seu processo de formação não tiveram experiências exitosas, que os levassem a olhar a sociedade em outra perspectiva. Ressalto que é necessário e possível fazer com que os universitários façam a leitura da realidade, considerando a reflexão histórica, ou seja, utiliza-se do pensar historicamente, para a compreensão da realidade atual, como algo dinâmico em constante transformação.

\section{Consciência Histórica: capacidade de ler e interpretar a realidade}

A realidade atual coloca vários desafios para os profissionais das mais diversas áreas do conhecimento, desde engenheiros, economistas, administradores a professores, de utilizarem a reflexão histórica. Mesmo sendo necessário, existem várias dificuldades que precisam ser enfrentadas, para que de fato esses sujeitos percebam o papel de se pensar historicamente. 
Diferentes leituras são possíveis de uma mesma temática, pois influiu a opção teórica e o ambiente que o sujeito vive. Em relação à História pode-se destacar três como sendo as principais perspectivas teórico-metodológicas ou visões de mundo, que possibilitam diferentes leituras de mundo. São elas: o positivismo, o historicismo e o materialismo histórico, no seu interior, outros desdobramentos podem ser realizados, pois a cada momento novas possibilidades são construídas, dependo das necessidades ou novas perguntas, novas respostas são construídas. Essas diferentes visões de mundo colocam distintas possibilidades para o processo de aprendizagem histórica.

O modelo positivista de ciência tornou-se insuficiente para interpretar a dinamicidade das relações sociais, sendo questionado e novas perspectivas foram construídas. Momento que o conhecimento passa a ser percebido como provisório, como parcial e em constante elaboração. Nesta perspectiva, pode-se destacar a Escola dos Annales e alguns autores da Escola de Bielefeld (se constituíram no interior do historicismo) e os Materialistas Históricos, que criticaram o positivismo, propondo outras possibilidades para as leituras de mundo. Para Fonseca (2004, p. 93-94), a Escola dos Annales e os Materialistas Históricos "apresenta, aos professores, a possibilidade de alargamento do campo da história, incorporando temas, ações e sujeitos até então marginais ao ensino".

As três visões de mundo da História contribuem, mas cada uma com suas especificidades. Aqui não se tem a pretensão de aprofundar essa análise, mas chamar a atenção dessas possibilidades, que levarão a leituras diferenciadas, bem como a ampliação do campo de análise. Ao concebermos a sociedade como dinâmica, de imediato é necessário pensar alternativas, que atendam essas expectativas.

O debate entre os historiadores tradicionais e os novos levou a uma renovação da História, com a incorporação de novas temáticas de estudo, considerados mais numa perspectiva interdisciplinar. Na busca dessas alternativas temos Jörn Rüsen, que dialogou com autores integrantes da Escola de Bielefeld, entre eles Koselleck. Rüsen estudou história, filosofia, pedagogia e literatura alemã na Universidade de Colônia. A sua pesquisa de doutorado foi sobre a teoria da história de Johann Gustav Droysen, um dos representantes teóricos do historicismo. Os diversos estudos desse autor contribuíram com a reestruturação 
do historicismo. Ressalta-se que, na sua perspectiva teórica-metodológica, portanto, o estudo e a reflexão histórica são necessidades permanentes da humanidade.

Assim, em relação a essa perspectiva teórica, importa analisar as proposições defendidas por Rüsen, em diversas obras, com objetivo de pensar o processo de constituição da consciência histórica. Para Rüsen (2001), alguns fatores da vida cotidiana constituem a consciência, em que o conhecimento histórico é um modo particular de um processo genérico e elementar para se constituir o pensamento humano. Por consequência, o pensamento histórico, que é uma articulação da consciência histórica, se constitui na vida prática dos homens, na experiência vivida e na interpretação do seu tempo. "A consciência histórica é a realidade a partir da qual se pode entender o que a história é, como ciência, e por que ela é necessária" (RÜSEN, 2001, p. 54-56).

A consciência histórica, a partir do pensar histórico dará a possibilidade de uma interpretação da sociedade, em que estarão articulando as experiências do passado com seu projeto de futuro, considerando, para tanto, as suas vivências do presente. Rüsen (2001, p. 56-57), então, explicita que:

\begin{abstract}
A consciência histórica será analisada como fenômeno do mundo vital, ou seja, como uma forma da consciência humana que está relacionada imediatamente com a vida humana prática. E este o caso quando se entende por consciência histórica a suma das operações mentais com as quais os homens interpretam sua experiência da evolução temporal de seu mundo e de si mesmos, de forma tal que possam orientar, intencionalmente, sua vida prática no tempo.
\end{abstract}

Assim, evidencia-se a necessidade e a importância de se desenvolver a consciência histórica, entendida como a maior capacidade de compreender a realidade e fazer as melhores escolhas, em que a sociedade terá de ser problematizada, aproveitando a experiência acumulada e as novas possibilidades de futuro. Podemos ainda recorrer a Rüsen (2001, p. 59), que concebe "o trabalho intelectual realizado pelo homem para tornar suas intenções de agir conformes com a experiência do tempo. Esse trabalho é efetuado na forma de interpretações das experiências do tempo". A consciência histórica, portanto, tem uma "função 
prática" de dar identidade aos sujeitos e fornecer à realidade em que eles vivem uma dimensão temporal, uma orientação que pode guiar a ação intencionalmente.

Rüsen defende a tese de que o homem tem de agir intencionalmente, o que é típico da vida humana, pois, ao satisfazer uma carência, logo se produzem outras, uma vez que,

o homem só pode viver no mundo, isto é, só consegue relacionarse com a natureza, com os demais homens e consigo mesmo se não tomar o mundo e a si mesmo como dados puros, mas sim interpretá-los em função das intenções de sua ação e paixões, em que se representa algo que não são (RÜSEN, 2001, p. 57).

Neste processo, fica evidente que a consciência histórica deverá ser desenvolvida. Na perspectiva de Rüsen (2001), todos os sujeitos têm "consciência histórica", mas não como algo que se constrói de uma vez, para sempre. Para esse autor,

\begin{abstract}
A consciência histórica não é algo que os homens podem ter ou não - ela é algo universalmente humano, dada necessariamente junto com a intencionalidade da vida prática dos homens. A consciência histórica enraíza-se, pois, na historicidade intrínseca à própria vida humana prática. Essa historicidade consiste no fato de que os homens, no diálogo com a natureza, com os demais homens e consigo mesmos, acerca do que sejam eles próprios e seu mundo, têm metas que vão além do que é o caso. A razão disso está no fato de que, nos atos da vida humana prática, há permanentemente situações que devem ser processadas, com as quais não se está satisfeito e com respeito às quais não se descansará enquanto não forem modificadas (RÜSEN, 2001, p. 78).
\end{abstract}

A consciência Histórica deverá ser desenvolvida, num processo de aprendizagem. O letramento histórico e o desenvolvimento de competências históricas, são necessários para que os sujeitos tenham condições de resolverem problemas de orientação. Rüsen destaca que

se "aprender" for entendido, fundamental e genericamente, como processo no qual as experiências e as competências são refletidas interpretativamente, esse conceito de aprendizado diz respeito ao que se discute aqui: a contribuição da ciência da História para o desenvolvimento daquelas competências históricas que são necessárias para resolver problemas práticos de orientação com auxílio do saber histórico (RÜSEN, 2010, p. 94). 
O autor ainda chama a atenção ao fato de que os processos de aprendizado histórico não ocorrem apenas no ensino de História, mas nos mais diversos ambientes que fazem parte da realidade dos aprendizes, mas, esses espaços formais são diferenciados, pois possibilita reflexões interpretativas. Numa sociedade complexa é preciso assumir a postura de um agir histórico; o que vale para os cidadãos de qualquer profissão, pois todas as ciências são históricas. Em cada momento surgem determinadas perguntas que devem ser respondidas a partir de um olhar sobre o que a humanidade produziu ao longo do tempo, e refletem os problemas e perplexidades com os quais o presente se debate. Assim sendo, a competência argumentativa torna-se relevante, o que, para Rüsen (2010, p. 120), "deve incluir as três dimensões, experiência ou saber, interpretação e orientação".

A aprendizagem é um processo dinâmico em que as várias áreas contribuem. Conforme Rüsen (2010, p. 106) "No aprendizado histórico dá-se a apropriação da "história": um dado objetivo, um acontecimento, que ocorreu no tempo passado, torna-se uma realidade da consciência, torna-se subjetivo".

Mais do que se apropriar de conteúdos elaborados por cientistas rigorosos, implica desenvolver capacidades ou competências ${ }^{5}$. Estudar História envolve refazer trajetórias, refletir sobre as experiências de vida e aproveitar as situações de aprendizagem que a vida oferece, a cada momento a cada novo tempo.

Assim, os conhecimentos históricos assumem outras possibilidades no processo de formação dos sujeitos, que deverão se qualificar e serem capazes de entender e compreender a dinâmica social dos acontecimentos, sua historicidade, tendo, dessa forma, mais elementos para perceber-se inserido numa realidade. Tanto na sociedade quanto na educação brasileira percebe-se que novas experiências estão sendo desenvolvidas, que podem qualificar o ensino da História na escola, através de atividades mais dinâmicas, com objetivo de formar sujeitos com maior capacidade de leitura de mundo.

Mesmo assim, alguns desafios precisam ser enfrentados para a qualificação do processo ensino aprendizagem, no contexto atual, que diz respeito também a uma maior valorização do professor. Para os alunos, desde a Educação Básica até

\footnotetext{
5 As competências discutidas por Rusen são diferentes dos defendidos, por exemplo, nos PCN's ou na BNCC.
} 
o universitário, fica evidente a relevância da reflexão histórica, do pensar histórico. Rüsen (2001) destaca que a História é exatamente o passado sobre o qual os homens deveriam olhar, par irem à frente em seu agir, conquistando o seu futuro.

Nesta perspectiva, essas novas possibilidades de ensinar e aprender, a escola precisaria trazer vivências de outros ambientes, que poderão ser analisados e compreendidos pelos sujeitos, através do estudo e debate. O desafio está em a escola criar possibilidades para que os sujeitos tenham condições de refletir sobre o ambiente que está inserido. De acordo com Diehl (2004, p. 45), "para começar a viver é preciso, portanto, ter consciência desse processo, é preciso adquirir as competências para a experiência consciente e o ordenamento das representações dessas experiências". Assim o desafio está em fazer uma maior relação com o contexto dos alunos, trazendo para o espaço escolar questões que estão percebendo no seu cotidiano, potencializando a aprendizagem histórica.

O ensino de história, estando em sintonia com o seu tempo, contribuiu para que os alunos tenham condições de lerem o seu entorno, sua realidade. Essa leitura será realizada considerando uma concepção de mundo, de sociedade de educação, pois os sujeitos que estão buscando fazer essa leitura estão implicados com essa realidade. Como Fenelon (1997, p. 124) já destacava

Toda a produção do conhecimento é fruto de um contexto social e, como tal carrega supostos e pressupostos. Ela carrega consigo, nesses supostos e pressupostos uma teoria sobre a história, a filosofia sobre a vida, sobre o mundo e, portanto, sobre a história, que, certamente, marcam a investigação.

Mesmo assim, os processos formais de aprendizagem fazem a diferença no processo de formação dos futuros profissionais. Fonseca (2004) ao analisar o ensinar e o aprender em História, destaca o papel formativo do ensino de história, pois

devemos pensar sobre a possibilidade educativa da história, ou seja, a história como saber disciplinar que tem um papel fundamental na formação da consciência histórica do homem, sujeito de uma sociedade marcada por diferenças e desigualdades múltiplas (FONSECA, 2004, p. 37-38).

Desta forma, torna-se necessário desenvolver o hábito de leitura, que nem sempre é valorizado ou pouco significativo para os jovens, pois acompanham 
poucos noticiários de jornais ou revistas, que trazem à tona o cotidiano vivido pelos sujeitos. Nessa mesma perspectiva, em algumas situações, as disciplinas que exigem muita leitura são, em boa medida, caracterizadas como sendo muito teóricas, não despertando o seu interesse. Em função disso, torna-se ainda mais relevante, trazer para espaço formal de aprendizagem, problemáticas do cotidiano.

Para qualificar a educação brasileira, torna-se necessário compreender, de forma mais precisa, quais são os desafios da educação na sociedade atual. Neste início do século XXI, percebe-se que é necessário qualificar os estudantes para lidar com as mudanças tecnológicas, mas também deverão estar preparados para assumirem com responsabilidade como pessoas e profissionais. A universidade, por exemplo, é uma instituição complexa. Frantz (2013) defende que ela

\begin{abstract}
deve ser um lugar de afirmação do diálogo, da argumentação, do debate entre os seres humanos, no campo das ideias, da Filosofia, da ciência, da arte, da política, da educação, da economia ou outras dimensões da vida, tendo por denominador comum a liberdade. A argumentação deve ter um sentido epistemológico, de construção do conhecimento, mas também de construção e reconstrução da universidade como instituição de valores e de sentidos de vida (FRANTZ, 2013, p. 23).
\end{abstract}

Na mesma perspectiva, Rüsen analisa a formação e destaca que ela pressupõe a capacidade de apreender em contextos dinâmicos, em que o refletir e o agir estão interligados. Torna-se necessário buscar, portanto, não pura e simplesmente a especialização, mas uma qualificação mais abrangente. Os sujeitos deverão manter-se atualizados, com capacidade de um aprender permanente. Rüsen (2010, p. 95) concebe formação como:

\footnotetext{
O conjunto das competências de interpretação do mundo e de si próprio, que articula o máximo de orientação do agir com o máximo de autoconhecimento [...] Formação opõe-se criticamente à unilateralidade, à especialização restritiva e ao afastamento da prática e do sujeito [...] refere-se à vinculação entre saber e agir exigida pela carência de orientação do sujeito agente, pois inserese na representação do todo que constitui a situação em que o agente deve lidar com os seus problemas.
}

Essas questões são destacadas por Freire (1996, 2005), ao considerar que quanto mais alguém se capacita como profissional, quanto mais sistematiza suas experiências, quanto mais se utiliza do patrimônio cultural, que é o patrimônio de 
todos e a todos deve servir, mais aumenta sua responsabilidade com os homens. Nas relações de uns com os outros, portanto, se constitui o senso crítico, possibilitando o assumir-se como um ser social e histórico, com um agir intencional mais coerente com o que o momento exige.

No sistema educacional brasileiro existem muitas indicações em relação aos desafios da aprendizagem no contexto atual. São leis, diretrizes, parâmetros, orientações, etc. que apontam o sentido em que deverão ser envidados os esforços educacionais do país. Até o final do século XX essas indicações estavam focadas especialmente nos conteúdos que deveriam ser estudados em cada nível de ensino e em cada área do conhecimento ou de formação profissional. A partir da Lei de Diretrizes e Bases da Educação Nacional de 1996, o foco central passou a ser o perfil do profissional em formação pela indicação de habilidades, capacidades e competências que devem ser estimuladas e desenvolvidas nos estudantes. Essa preocupação está presente e colocada em todos os níveis de ensino, desde a escola a universidade.

Ao analisar a historiografia e os documentos oficiais constata-se que ocorreram avanços em relação aos debates sobre a História, sendo possível reafirmar a importância do conhecimento histórico numa sociedade em constante mudança. Os Parâmetros Curriculares Nacionais do Ensino médio - PCN+ (BRASIL, 2000, p. 70), por exemplo, destacam que "contextualizar as ações dos sujeitos nos diferentes espaços de ação do cotidiano em suas esferas públicas e privadas e nas múltiplas dimensões - econômica, política, social e cultural - em que as estruturas e as conjunturas estão presentes".

Assim, os PCN+ também demonstra a necessidade da contextualização, mas nem sempre isso é percebido, por todos, como importante, pois as propostas necessitam ser constantemente revistas, reescritas para atender os desafios do momento histórico. Mesmo assim, para avançarmos na perspectiva da constituição do sujeito histórico, através do desenvolvimento da consciência histórica, tornase necessário retomar a categoria central da História, que é o tempo, em que implica relacionar o presente, passado e futuro, a historicidade e o pensar histórico, que precisam estar presentes nos diferentes anos do processo de formação dos estudantes. 
Nesta perspectiva, torna-se necessário identificar alternativas que possam contribuir na qualificação do ensino de História, que nos remete à Didática da História analisada por Rüsen (2012, p. 16), pois o diálogo com a ciência da História ajudaria no repensar do ensino de História, pois se "concebe como ciência do aprendizado histórico e não como ciência da transmissão do conhecimento histórico produzido pela ciência da história".

Rüsen recomenda uma Didática da História dinâmica, como bem destaca o autor,

[...] de um lado, o processo de aprendizagem é constante, por isso sujeito a mudanças, correções, suplementações ao longo de toda a vida (e vale para todos, não apenas para alunos e alunas). Por outro lado, seus conteúdos e práticas de ensino estão diuturnamente confrontados com a evolução das circunstâncias dos tempos, o que requer o dinamismo da crítica e da renovação de métodos e atitudes. Em ambos os casos importa descobrir, analisar, criticar e organizar os modelos de interpretação existentes, desejáveis, sustentáveis, viáveis, aplicáveis. Para tanto se requer a experiência prática de docentes como de alunos e alunas, em cada um e em todos os níveis da obtenção e da evolução da consciência histórica (RÜSEN, 2012, p.11)

A didática compreendida dessa forma contribuiu para um empoderamento da História, pois ter consciência Histórica para esse autor não é simplesmente conhecer fatos que fazem parte de um contexto, mas percebê-los como uma construção humana, em que várias leituras são possíveis, desde que relacionado há outros tempos e espaços. Assim, a categoria do tempo, combinado com outras perspectivas, que refletem o tempo, contribuem para uma leitura qualificada da realidade, como por exemplo, o espaço, historicidade, memória. Essas categorias tornam-se fundamentais para a leitura do contexto, de uma realidade.

Rüsen (2001, p. 78) destaca que "a consciência histórica enraíza-se, pois, na historicidade intrínseca à própria vida humana prática". Assim pode-se destacar a importância do pensamento histórico, que nos remete a matriz disciplinar (interesses, ideia, métodos, formas e funções) proposto pelo autor, pois ressalta que a vida prática é o ponto de partida, bem como de chegada. Ressalto que a consciência histórica não alcança um estágio final, nunca está concluída, porém, ampara-se em conhecimentos dinâmicos, relacionando presente, passado e futuro, o que possibilita uma leitura de mundo, de realidade, como dinâmica e em 
constante transformação. Para tanto, informações são interiorizadas, organizadas e ao narrar fica evidente a utilização da consciência histórica (como ferramenta mental), utilizando-se disso para a sua orientação no cotidiano pessoal e social.

Isabel Barca, da Universidade do Minho, destaca que a consciência história, "ocorre quando a informação inerte, progressivamente interiorizada, se torna ferramenta mental do sujeito e é utilizada, com alguma consistência, como orientação no quotidiano pessoal e social" (BARCA, 2012, p. 40). Nesta perspectiva, muitos são os desafios para a qualificação do processo ensino aprendizagem, dando condições para que os sujeitos analisem a sociedade em que vivem.

Para o enfrentamento dessa problemática, os alunos, durante o seu processo de formação, deverão perceber que, além de ter domínio de conteúdos, deverão estar capacitados a lidar com categorias, como: o tempo - presente, passado e futuro -, a historicidade, o processo, o pensar histórico, espaço, entre outros, como fundamentais para o desenvolvimento da consciência histórica como fundamentais para a compreensão da sociedade.

\section{Considerações Finais}

É necessário repensar profundamente a dinâmica da educação e desenvolver experiências pedagógicas que possibilitem aos estudantes, ao invés de simplesmente memorizar conteúdos, incrementar suas habilidades, para que tenham condições de utilizar categorias históricas, para análise qualificada da realidade. O aprendizado histórico é complexo, pois se podem incorporar informações históricas na forma como alguns assistem à televisão, passivamente, mas não é o que se pretende com a reflexão histórica aqui analisada. Isso se identifica como aprendizado, porém é uma mera repetição, não possibilitando o desenvolvimento de uma "real aprendizagem", na perspectiva analisada por Rüsen e Isabel Barca.

Alternativas estão sendo construídas e desenvolvidas nos espaços formais de aprendizagem, que visam qualificar o processo ensino e aprendizagem. A incorporação de outras fontes e linguagem, tais como: a música, a fotografia, as charges, a internet, etc, além do livro didático e paradidático, são materiais 
diferenciados para serem utilizados em sala de aula. A proposição de novas metodologias pode contribuir para despertar o interesse do aluno pelo estudo histórico, conhecendo e perceber-se inserido na realidade.

Assim, entretanto, torna-se necessário fomentar o apoio a novas propostas, bem como garantir a efetivação das já existentes. Neste sentido, a busca pelo desenvolvimento da consciência histórica, através de uma Aprendizagem Situada, em que as ideias prévias dos professores e alunos contribuem para um repensar do processo pedagógico, garantindo, desta forma, a concretização do aprendizado histórico. A narrativa representa uma possibilidade para demonstrar o desenvolvimento da consciência histórica.

Alguns desafios deverão ser enfrentados, em que o avanço de pesquisas em relação à Didática da História (Rüsen, 2001, 2010, 2012) podem fomentar e qualificar o debate sobre o processo de ensino e aprendizagem histórica. Propostas diferenciadas estão sendo desenvolvidas, mesmo assim, mais estudos precisam ser realizados, avançando na perspectiva que os alunos, em vários momentos destacam, que é o de buscar uma maior aproximação da teoria com a prática, com a realidade dos mesmos.

Para pensar o aperfeiçoamento dos espaços formais de aprendizagem, tornase necessário apoiar os professores dos diversos níveis de ensino. O esforço é do coletivo, por meio de uma articulação interinstitucional, pois esses profissionais deverão constituir-se em pesquisadores de sua prática, num processo de aprendizado contínuo. A vida acadêmica é uma constante busca - pesquisar é preciso.

\section{Referências}

BARCA, Isabel. Ideias chave para a educação histórica: uma busca de (inter)identidades. Hist. R., Goiânia, v. 17, n. 1 p. 37-51, jan./jun. 2012. Disponível em: http://www.revistas.ufg.br/index.php/historia/article/view/21683/12756. Acesso em: 12 ago. 2013.

BRASIL. Lei no 9.394, de 20 de Dezembro de 1996. Estabelece as diretrizes e bases da educação nacional. Brasília: Presidência da República, 1996.

BRASIL. Ministério da Educação. Parâmetros curriculares nacionais - ensino médio - ciências humanas e suas tecnologias. Brasília: MEC, 2000. 
DIEHL, Astor. Experiência e sentido: considerações sobre os campos de trabalho para a didática da história. In: ZARTH, P. (org.). Ensino de história e educação. Ijuí: Ed. Unijuí, 2004.

FENELON, Déa. Pesquisa em história, perspectivas e abordagens. In: FAZENDA, I. Metodologia da pesquisa educacional. 4. ed. São Paulo: Cortez, 1997.

FONSECA, Selva G. Didática e prática de ensino de história. 2. ed. Campinas: Papirus, 2004.

FRANTZ, W. Reflexões sobre universidade. In: ANDRADE, E.; ANDRIOLI, L. ; FRANTZ, W. Educação no contexto da globalização: reflexões a partir de diferentes olhares. Ijuí: Ed. Unijuí, 2013.

FREIRE, Paulo. Pedagogia da autonomia: saberes necessários à prática educativa. São Paulo: Paz e Terra, 1996.

FREIRE, Paulo. Pedagogia do oprimido. Rio de Janeiro: Paz e Terra, 2005.

MARQUES, Mario O. Universidade emergente: o ensino superior brasileiro em Ijuí (RS), de 1957 a 1983. Ijuí: Fidene, 1984.

RÜSEN, Jörn. Aprendizagem histórica: fundamentos e paradigmas. Curitiba: W. A. Editores, 2012.

RÜSEN, Jörn. História viva: teoria da história III: formas e funções do conhecimento histórico. Brasília: UnB, 2010.

RÜSEN, Jörn. Razão histórica: teoria da história I: fundamentos da ciência histórica. Brasília: UnB, 2001. 194 p.

SANTOS, Milton. Por uma outra globalização: do pensamento único à consciência universal. 19 ed. Rio de Janeiro: Record, 2010.

SEN, Amartya; KLIKSBERG, Bernardo. As pessoas em primeiro lugar: a ética do desenvolvimento e os problemas do mundo globalizado. São Paulo: Companhia das Letras, 2010. 